\title{
A Survey of Dermatophytes Isolated from Cows and Sheep in Iraq
}

\section{Sudad Jasim Mohammed}

Microbiology Department, Veterinary Medicine College, Baghdad University

\section{Accepted on 17/7/2011}

\section{Summary}

A total of 100 animals were examined during the period of beginning of September-2010 till the end of March 2011 at dept of Microbiology college of Veterinary Medicine Baghdad University Baghdad Iraq. These animals include $50 \mathrm{cow}$ and 50 sheep. Hairs and scales were submitted to direct $\mathrm{KOH}$ mount smear and culture on modified Sabouraud's Dextrose agar medium The direct smear was positive in $40(80 \%)$ for both cows and sheep while the growth of dermatophyte was positive in $35(70 \%)$ and $38(76 \%)$ for cows and sheep respectively. Species identification revealed the presence of Trichophyton rubrum ( 19 isolates ) Trichophyton verrucosum ( 10 isolates ) Trichophyton mentagrophytes ( 5 isolates ) and Microsporum canis ( one isolate) in cow while Trichophyton rubrum (22 isolates) Trichophyton verrucosum ( 2 isolates ) and Trichophyton mentagrophytes ( 14 isolates) was recorded in sheep.

Keyword: Dermatophytes Trichophyton verrucosum , Trichophyton mentagrophytes, Microsporum canis, Trichophyton rubrum.

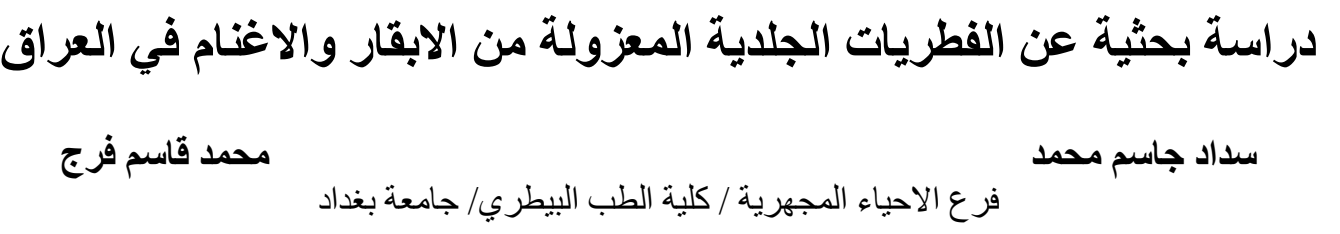

\section{الخلاصة}

تم فحص مائة حالة من الابقار والاغنام خلال الفترة من بداية شهر أيلول 2010 الى نهاية

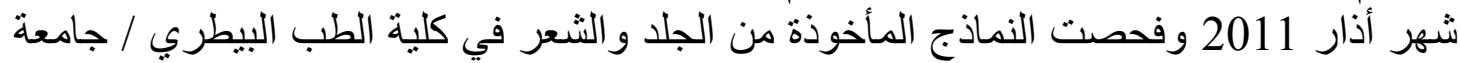

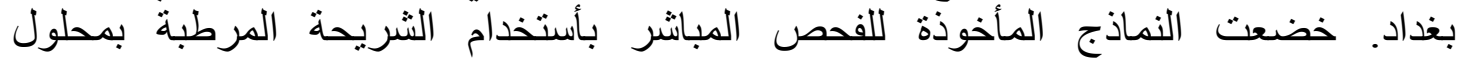

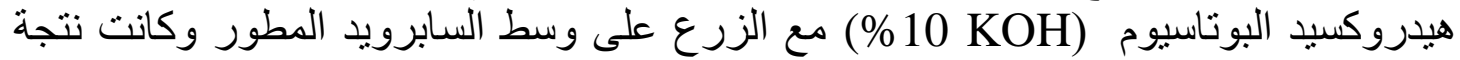
الفحص المباشر 40 (80\%) لكل من الابقار بينما كان نمو الفطريات الجلدية موجبة في في 35

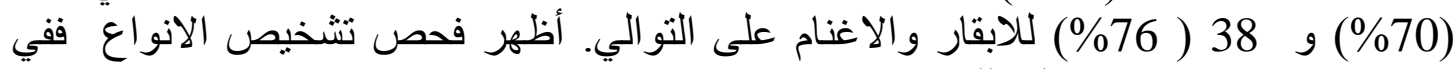
الابقار وجود 19 Trichophyton rubrum و Trichophyton mentagrophytes و 5 Trichophyto verrucosum عزلة واحدة للنوع Microsporum canis بينما في الاغنام شخصت 22 عزلة من النوع Trichophyton rubrum من النوع عentagrophyte. 


\section{Introduction}

Dermatophytes are fungi that require keratin for growth. These fungi can cause superficial infections of the skin hair and nails They are spread by direct contact from other people ( Anthropophilic organisms ) animals ( Zoophilic organisms) and soil (Geophilic organisms ) as well as indirectly from fumiest (1). Dermatophytes infection usually refer to as Tinea are caused mostly by the genera Epidermophyton Microsporum and Trichophyton.

Variation in the distribution pattern of dermatophytes infection a many different countries of the world are evident in the studies ( 2 - 6 ). This distribution pattern of dermatophytes infections in different parts of the world has been attributed to factors of climate life - style and prevalence of immunodeficiency disease in the community and also the reluctance of patients to seek treatment because of embarrassment or minor nature of disease unless the condition becomes sufficiently serious to effect the quality of life (7).

\section{Materials and Methods}

A total of 100 animals were examined during the period of beginning of September 2010 till the end of March 2011 at dept of Microbiology college of Veterinary Medicine Baghdad University Baghdad Iraq These animals include 50 cows and 50 sheep hairs and scales were submitted to microscopic examinations after immersion in $10 \%$ potassium hydroxide solution with gentle heating Hairs and scales from active outer border of the lesions of all animals were inoculated on modified Sabouraud's Dextrose agar containing chloramphenical ( $005 \mathrm{mg} / \mathrm{ml})$ and cyclohexmide $(05 \mathrm{mg} / \mathrm{ml})$ Culture were incubated at $28 \mathrm{c}$ with daily observation for a period of $4-5$ weeks before they were considered negative The identification of dermatophyte species was based on the gross and microscopic cultural characteristics produced on this standard medium according to Emmon et al ( 8 ) and Rippon ( 9 ).

\section{Results}

A total of 50 cows were examined. Twenty five ( $50 \%$ ) cases were positive by both direct $\mathrm{KOH}$ mounts smear and culture Fifteen $(30 \%)$ cases were culture negative after six weeks incubation at room temperature ( $28 \mathrm{c}$ ) although the direct $\mathrm{KOH}$ mount examination was positive. The remaining 10 (20\%) cases gave a positive culture result although the direct $\mathrm{KOH}$ mount smear examinations were negative ( table1). 
A total of 50 sheep were examined. Twenty eight ( $56 \%$ ) cases were positive by both directed $\mathrm{KOH}$ mount smear and culture Twelve ( $24 \%$ ) cases were culture negative after six weeks incubation at room temperature although the direct $\mathrm{KOH}$ mount examinations was positive. The remaining $10(20 \%)$ cases gave $\mathrm{KOH}$ mount smear examination were negative (table1).

Table ( 2 ) shows that the higher incidence of infections was obtained from rural areas $(70 \%)$ and (64\%) in both cows and sheep respectively while lower incidence of infection was recorded from urban areas (30\%) and (36\%) in both cows and sheep respectively. The frequency of infections in different animals regardless of their localities were shown in (figure 1 ) Sheep cases revealed the highest percentage of positive cases ( 38 ) followed by cows ( 35 ). Thirty five isolates were obtained from fifty cases belong to cows They were distributed into the following : 19 isolates (54.3\%) were Trichophyton rubrum followed by Trichophyton verrucosum 10 isolates ( $28.6 \%$ ) Trichophyton mentagrophytes 5 isolates ( $143 \%$ ) and Microsporum canis was one isolate (28\%) hese species were identified by the conventional methods (table 3 ). While 38 isolates were obtained from fifty cases belong to sheep They were distributed into the following : Trichophyton rubrum 22 ( $579 \%$ ) isolates were recorded the highest number followed by Trichophyton mentagrophytes 14 (36 8\%) isolates and Trichophyton verrucosum was $2(53 \%)$ isolates ( table 3$)$.

\section{Discussion}

In this investigation ringworm infection was diagnosed in domestic animals namely cows and sheep As in other infections disease definitive diagnosis of ringworm infection depends upon the demonstration of the causative agent Diagnosis on the clinical appearance of the lesions is difficult except in the exceptional classical ringed lesions (10). Out of the positive cases of ringworm in sheep $28(56 \%)$ and cows $25(50 \%)$ were detected by both direct $\mathrm{KOH}$ examination and culture respectively .

The higher percentage of negative culture from positive direct examination was mostly due to frequent contamination with saprophytes which over whelmed the medium and prevented the appearance of dermatophyte colonies even in the presence of cycloheximide in the medium. The higher percentage of positive cases in sheep (38\%) and cows (35\%) was recorded from rural areas in contrast to the urban areas One explanation for this high incidence was the possibility of contagious infection among animals sharing common shelters This possibility was confirmed by isolating the same etiological agents Moreover many of the infected animals 
The Iraqi J. Vet. Med. 35 ( 2 ): 40 - 45; 2011

in the urban areas were already under treatment when specimens were taken from them for diagnosis. This led to false negative result. The importance of the dermatophytes of animal origin is clearly demonstrated by the species isolated from animals in the rural region ( 4 ). In this study three species of dermatophytes were identified out of 38 positive culture of sheep These species were Trichophyton rubrum (22 isolates) Trichophyton verrucosum ( 2 isolates ) and Trichophyton mentagrophytes ( 14 isolates ) while four species of dermatophytes were identified out of 35 positive culture for cows There species were Trichophyton rubrum ( 19 isolates ) Trichophyton verrucosum ( 10 isolates ) Trichophyton mentagrophytes ( 5 isolates ) and Microsporum canis ( one isolate ). Our results was in agreements with the findings of others $(12,13$ and14 ).

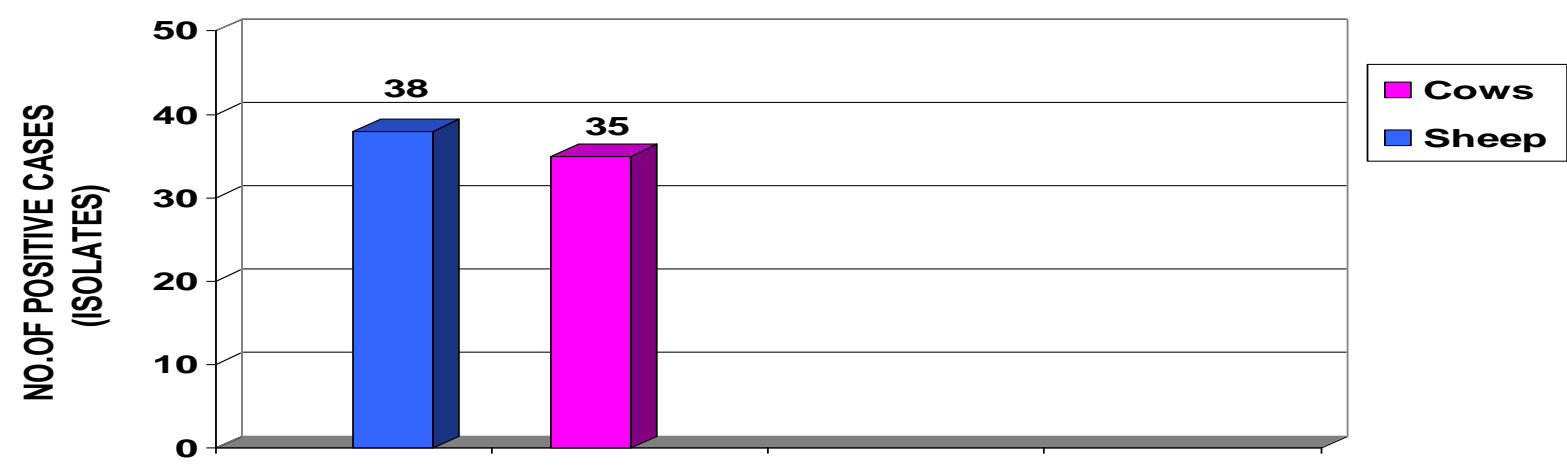

Types of animals

Figure (1): Incidence of dermatophytes infection in different types of animals.

Table (1): Relation between direct KOH mount smear and direct culture of 50 cases of both Cows and sheep.

\begin{tabular}{|c|c|c|c|c|}
\hline Type of animal & \multicolumn{2}{|c|}{ Cows } & \multicolumn{2}{|c|}{ Sheep } \\
\hline Examined cases & NO. & $\%$ & NO. & $\%$ \\
\hline D + & 25 & 50 & 28 & 56 \\
\hline $\mathbf{D}+$ & 15 & 30 & 12 & 24 \\
\hline D - $\quad$ C + & 10 & 20 & 10 & 20 \\
\hline Total & 50 & 100 & 50 & 100 \\
\hline
\end{tabular}

$\mathrm{D}+$ = positive direct $\mathrm{KOH}$ exam.

$\mathrm{D}$-- = negative direct $\mathrm{KOH}$ exam.

$\mathrm{C}+=$ positive culture

$\mathrm{C}-=$ negative culture 
Table(2): The incidence and distribution of dermatophytes infection in Cows and sheep according to their location.

\begin{tabular}{|c|c|c|c|c|c|}
\hline \multirow{3}{*}{ Animals } & $\frac{\text { Urban }}{\text { No. }}$ & $\%$ & $\frac{\text { Rural }}{\text { No. }}$ & $\%$ & $\begin{array}{c}\text { Total } \\
\text { No. }\end{array}$ \\
& & & & & \\
\cline { 2 - 6 } & Infected/ examined & & Infected/ examined & & \\
\hline Cows & $15 / 50$ & 30 & $35 / 50$ & 70 & 100 \\
\hline Sheep & $18 / 50$ & 36 & $32 / 50$ & 64 & 100 \\
\hline
\end{tabular}

Table (3): The number and percentage of dermatophytes species isolated from 50 Cows and 50 Sheep.

\begin{tabular}{|c|c|c|c|c|}
\hline \multirow{2}{*}{ Species of dermatophytes } & \multicolumn{2}{|c|}{ Cows } & \multicolumn{2}{|c|}{ Sheep } \\
\hline & NO. & $\%$ & NO. & $\%$ \\
\hline Trichophyton rubrum & 19 & 54.3 & 22 & 57.9 \\
\hline Trichophyton verrucosum & 10 & 28.6 & 2 & 5.3 \\
\hline Trichophyton mentagrophytes & 5 & 14.3 & 14 & 36.8 \\
\hline Microsporum canis & 1 & 2.8 & $\mathbf{0}$ & $\mathbf{0}$ \\
\hline Total & 35 & 100 & 38 & 100 \\
\hline
\end{tabular}

\section{References}

1. Hanier BL ( 2003 ). Dermatophytes infection American Family physician ; $67: 101-108$.

2. Ayadi A Borgi N and Makni F (1993). Prevalence of superficial mycoses in Prevailing fungi pattern of infection Dermatol . $190: 39-42$.

3. Staats CC and Korstanje M (1995). J Fungal infection in Netherland Bull Soc pathol Exotique : $86: 188-190$.

4. Weitzman I ; and Summerball RC (1995). The Dermatophyte clin Microbiol Rev : 8: $240-259$.

5. Ellabib M S and Khalife ZM (2001). Dermatophytes and other fungi associated with skin mycoses in Libya Ann Saudi Med ; $21: 3$ - 4.

6. Anosike JC Keke IR Anozie JC and obiukwu CE ( 2005). Dermatophytes infection and Environmental Management. J Appl Sci. 9:21 - 25

7. Al Sheikh H ( 2009). Epidemiology of Dermatophytes in the Eastern Province of Saudi Arabia . Res J Microbiol : 4: 229 -234.

8. Emmon 's CW Binford CH Ut JP and Kwon Chung K J (1977). Medical mycology Lea and Fabiger. Philadelphia. 165. 
The Iraqi J. Vet. Med. 35 ( 2 ): 40 - 45; 2011

9. Rippon JW( 1988). Medical mycology The fungi and the pathogenic actinomycetes W B Saunders. Philadelphia $3^{\text {rd }}$ ed .196.

10. Jungerman PF and Schwartzman RM ( 1972). Veterinary Medical Mycology Lea and Febriger Philadelphia.

11. Blank F (1956). Dermatophytes of animal origin transmission to man. Amer J Med Sci . $224: 302-316$.

12. Hay RJ (1993) Superficial mycoes In ; fungi and skin disease Mosby Wolfe London . 13-27.

13. Hay RJ (1999). How common one fungal infection in Europe Eighth congress of the European Academy of Dermatology and Venereology ( EADV) .

14.Aly R (1994). Ecology and epidemiology of dermatophyte infections. J Am Acad Dermatol .31:21-25. 